\title{
Phytoplankton Index of Biological Integrity (P-IBI) in Several Marshes, Southern IRAQ
}

\author{
Bahram K. Maulood ${ }^{1}$, Abdul Hameed M. Jawad Alobaidy ${ }^{2}$, Azhar Alsaboonchi ${ }^{3}$, Haider S. Abid $^{4}$, \\ Ghasak S. Alobaidy ${ }^{1}$ \\ ${ }^{1}$ Twin Rivers Institute, American University of Iraq-Sulaimani, Sulaimani, Iraq; ${ }^{2}$ Environmental Research Center, University of \\ Technology, Baghdad, Iraq; ${ }^{3}$ Department of Fisheries and Marine Resources, University of Basrah, Basrah, Iraq; ${ }^{4}$ Department of \\ Biology, College of Science for Women, University of Baghdad, Baghdad, Iraq. \\ Email: bahram.khider@auis.org, jawaddhy@yahoo.co.in, azharalsaboonchi@yahoo.com, haider.abid@gmail.com, \\ Ghasak.sabah@hotmail.com
}

Received January 20, 2011; revised February 24, 2011; accepted April 10, 2011.

\begin{abstract}
Indices of Biological Integrity (IBIs) are being increasingly used as useful and direct tools for assessing general health of aquatic ecosystems. Although such ecosystems in Iraq, especially the southern marshes, underwent severe alterations during the last two decades, including extensive desiccation in the 1990s, such tools are largely lacking. Phytoplankton Index of Biological Integrity (P-IBI) was developed from data collected seasonally from 2005 up to 2007 in different sites of the southern marshes of Iraq to evaluate the trend of these ecosystems based on phytoplankton data. Ten metrics were selected for measuring P-IBI for the first time in Iraq as a proposed project from Nature Iraq and Twin Rivers Institute, American University of Iraq-Sulaimani. Although generally fluctuated both spatially and temporally, mean P-IBI scores showed better conditions in Al Hawizeh marsh (Good) as compared to the Central and West \& East Al Hammar marshes (Fair to Good). However, the results generally indicated evidence of improvement at the Central and West \& East Al Hammar marshes, whereas no recovery of the status of water was evident throughout the data obtained at Al Hawizeh marsh. Values were generally higher in winter. These observations clearly reflect the relative stability of the Hawizeh marsh ecosystem which was not subject to the desiccation process in the 1990s, while the severely dried systems of the Central and Hammar marshes are showing positive responses to the restoration efforts that were started after 2003. Among the ten metrics comprising the index, relative abundance of diatoms had the most prominent effect on the P-IBI value in the three marshes. Metrics such as chlorophyll- a concentration and relative abundance of Cyanophyta and Chlorophyta also played a significant role in determining the index value. Continuous monitoring based on the selection of the most suitable metrics is recommended.
\end{abstract}

Keywords: IBI, Nature Iraq, Marshes, Aquatic Ecology

\section{Introduction}

Index of biological Integrity (IBI) has been proven to be an important assessment tool for evaluating the resource quality of aquatic ecosystems [1]. Multimetric indices are increasingly common as resource and ecosystem management tools and are often more robust than their component metrics [2].

Ecologists have tried to measure ecosystem health and its integrity through the development of indices of biological integrity. Karr [3] was the first who devised an index to measure biological integrity in a stream using fish indicator species in Central Illinois. This index has been adapted and modified to use benthic macroinvertebrates as indicators and to evaluate the integrity of es- tuarine ecosystems [4,5]. Different measures of phytoplankton taxonomy, abundance and biomass have been used extensively to document the effects of eutrophication [6,7]. Multible phytoplankton metrics have been used in ecosystem indices for several estuaries [8]. The planktonic index of biological integrity was developed recently using zooplankt on and phytoplankton data [9].

The phytoplankton index of biological integrity (P-IBI) has been proved to be a management tool to assess phytoplankton community status relative to nutrient and light conditions in an ecosystem [2].

In measuring the physical and chemical properties of water, biological properties have often been overlooked [10]. Likewise, monitoring the concentrations of various 
chemicals often misses a number of human-induced problems. In addition, physical and chemical attributes usually don't serve well as surrogates for the measure of biological properties [11,12]. A more informative method would be to use biological data to measure community directly, rather than the use of physical and chemical measures that indirectly affect the biota.

Zooplankton and phytoplankton communities vary in their composition and abundance over time, both on seasonal and inter-annual basis $[13,14]$. Therefore, studies on seasonal succession of zooplankton and phytoplankton communities will provide an important paradigm to general ecology [15].

Plankton is sensitive to environmental changes [16] and comprises a necessary component of a useful monitoring program. Further, plankton is inexpensive to collect, samples can be stored for long periods, don't take up large amount of space and historical samples can be compared with current samples. Arguably, all components of a water body function are influenced in major ways by the dynamics of phytoplankton and zooplankton. Phytoplankton are the primary producers whereas zooplankton is the central trophic link between primary producers and fish $[17,18]$.

Phytoplankton has been used as indicators of nutrient conditions as well as pollution in water [19]. Rawson [20] discussed the ratio of centric to pennate diatoms as being indicator of trophic conditions. Trophic status of any water body may be indicated by different phytoplankton taxa or a number of ratios between different groups [21]. Diatoms could be used for monitoring environmental changes including changes in trophic status of water bodies [22].

Macroinvertebrates are more sensitive to changes in habitat diversity and quality than to changes in water quality to which diatoms respond in a better way. Therefore, biological assessments based on both communities are useful for describing the ecological status of an ecosystem. The effect of enrichment of organic pollution and eutrophication as a consequence lead to the use of diatoms for biomonitoring the aquatic ecosystems [23].

In general, biological integrity is an ecosystem property that can be defined as the capability of supporting and maintaining a balanced, integrated, and adaptive community of organisms having a species composition, diversity and functional organization comparable to that of natural habitats of the region [11].

The P-IBI uses different metrics. Sommer et al. [13] classified values from these planktonic metrics in order to reflect different levels of trophic status. Lacouture et al. [2] have chosen thirty eight planktonic metrics; different combinations of these metrics were scored and used to build phytoplankton community indices for different reasons in four stations in Chesapeake Bay. Scoring criteria for each metric were evaluated for their ability to discriminate between least impaired and impaired conditions. Different statistical tests were applied in order to identify the most discriminatory metric. Solimini et al. [24] calculated thirty one metrics based on taxa richness, pollution tolerance, habit and functional feeding groups in order to develop a multimetric index of ecological integrity of mountain ponds in central Italy.

The purpose of the present project is to apply a metric index of biological integrity for phytoplankton to be used in the evaluation of the health of the marshes' water in southern Iraq. In parallel, part of the project was dealing with zooplankton index of biological integrity that is in the process of publishing. Application of IBI in the southern marshes for the first time in Iraq will undoubtedly encourage other scientists to apply it in other parts of Iraq. Nevertheless, this study comes under the project of Ecological Indices in our country that has been proposed and supported by Nature Iraq and Twin Rivers Institute, American University of Iraq-Sulaimani in order to reorganize the parameters used for water monitoring in Iraq.

\section{Methods}

Data used in the present study were obtained from Nature Iraq's Key Biodiversity Areas (KBA) project. Briefly, phytoplankton samples were collected on monthly basis from different sites and different locations in $\mathrm{Al} \mathrm{Hawizeh}$ Marsh, Central Marsh and East and West of Al Hammar Marsh (Figure 1). Data were arranged seasonally (summer and winter from 2005 to 2007).

Phytoplankton samples were taken by a $20 \mu$ mesh size net. Known volume of water was filtered for quantity studies. Identification of species was done by a compound microscope and the following references [25-30] were used.

Total density of species was calculated by the sum of monthly densities of each species. Then species were placed according to proper metrics. Phytoplankton metrics used for this analysis included: phytoplankton density $\left(\right.$ cell/ $/ \mathrm{L}^{3}$ ), relative abundance of Centrales, relative abundance of Pennales, relative abundance of diatoms, relative abundance of Chlorophyceae, relative abundance of Cyanophyceae, relative abundance of inedible algae, relative abundance of edible algae, concentration of Chlorophyll- $a(\mathrm{mg} / \mathrm{l})$ and richness index.

Metric raw data (percentages of densities) were converted into metric scores after being subjected to a scale of thresholds of 1, 3 and 5 [3] (Table 1). The development of these thresholds was performed according to [31] based on the existing historical data and professional judgment. Thus, a threshold of 5 was given for metrics 


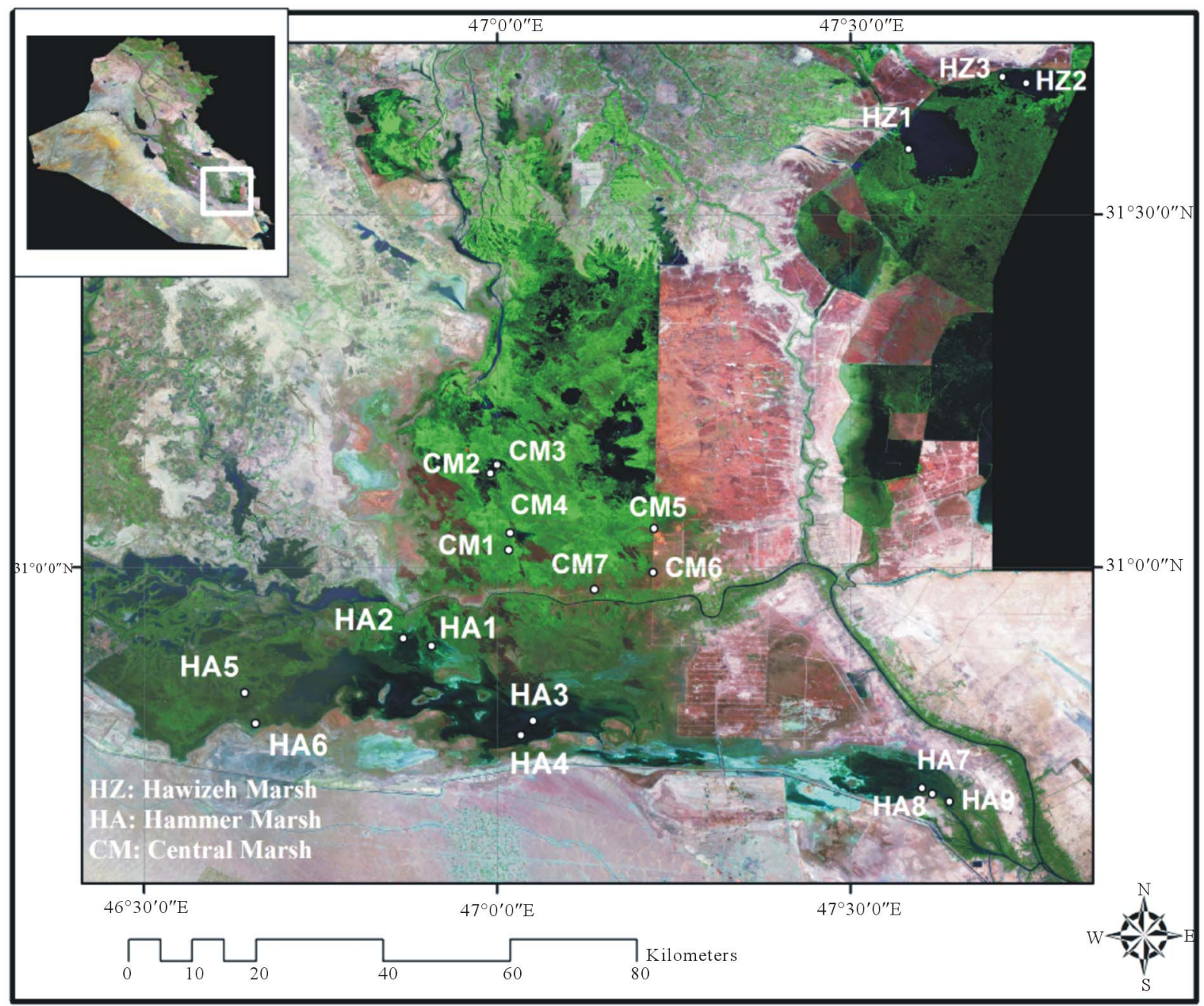

Figure 1. Study sites in Al Hawizeh, Central, and Al Hammar marshes.

Table 1. Scoring criteria of different sites of the Marshes.

\begin{tabular}{|c|c|c|c|}
\hline \multirow{2}{*}{ Metrics } & \multicolumn{3}{|c|}{ Scoring Criteria } \\
\hline & 1 & 3 & 5 \\
\hline Phytoplankton Density & $>4000$ & $4000-2000$ & $2000-1000$ \\
\hline R.A. of Centrales & $>35 \%$ & $35 \%-25 \%$ & $<20 \%$ \\
\hline R.A. of Pennales & $30 \%$ & $30 \%-40 \%$ & $40 \%-95 \%$ \\
\hline R.A. of Diatoms & $<30 \%$ & $30 \%-60 \%$ & $>60 \%$ \\
\hline R.A. of Chlorophyceae & $<5 \%$ & $5 \%-18 \%$ & $>18 \%$ \\
\hline R.A. of Cyanophyceae & $>30 \%$ & $30 \%-20 \%$ & $<20 \%$ \\
\hline Concentration of Chlorophyll-a & $>5$ & $5-3$ & $<3$ \\
\hline R.A. of inedible algae & $>20 \%$ & $20 \%-15 \%$ & $<15 \%$ \\
\hline R.A. of edible algae & $<60 \%$ & $60 \%-80 \%$ & $>80 \%$ \\
\hline Richness Index & $<30$ & $30-70$ & $>70$ \\
\hline
\end{tabular}

R.A. = Relative Abundance. 
that has values equal or near to reference condition, 3 was given to those of medium conditions and 1 to those of worst conditions. In addition, according to Astin [32], these values reflect those more traditional measures of trophic status. The sums of these metric scores for each site were calculated seasonally as the P-IBI. However, the maximum value of P-IBI in this study would be 50, derived from multiplying the number of metrics (10) by the maximum score for each metric (5). The final index scores were grouped in five rating categories of "Excellent", "Good" , "Fair", "Poor" and "Very Poor" as in Table 2 [3]. A value close to 50 indicates that streams biology is equivalent to what would be found in a natural condition. A value close to 10 indicates a poor biological condition within the ecosystem. Table 2 shows the cutoff values for the IBI scores and qualitative interpretation according to Karr [3]. The P-IBI values were categorized as Excellent, Good, Fair, Poor and Very Poor. The minimal and maximal cutoff values for each category represent the outcome of multiplying the minimal (i.e., 1) and the maximal (i.e., 5) scoring criteria by the total number of metrics comprising the index (i.e., 10).

\section{Results}

Three sites were selected at $\mathrm{Al}$ Hawizeh Marsh [Umm Al Niáj (HZ1), Al Udhaim (HZ2) and Al Sewalif (HZ3)]. The results of P-IBI ranged between 34 - 50 (Fair to Excellent ecosystem condition) indicating the fluctuation in the status of these sites. The higher values were observed in HZ2 site during winter 2007, while the lower values were observed in HZ1 and HZ2 sites during summer 2006 and 2007 respectively (Table 3). B-IBI values in HZ1 were reduced from 42.0 to 36.0 and from 43.0 to 38.0 through summers 2005 to summer 2007 and winter 2006 to winter 2007 respectively. This phenomenon was evident at site HZ2 through summer. In contrast, an improvement was observed, where the B-IBI values were increased from 46.0 to 50.0 through winter 2006 and 2007 respectively. An improvement of the values was observed at site HZ3 in summer throughout 2005, 2006 and 2007. Generally, HZ1, HZ2 and HZ3 sites display

Table 2. Cutoff values of IBI scores and relevant qualitative interpretations for ecosystem condition.

\begin{tabular}{ll}
\hline 10 Metric IBI Score & Ecosystem Condition \\
\hline $46-50$ & Excellent \\
$38-44$ & Good \\
$28-36$ & Fair \\
$18-26$ & Poor \\
$10-16$ & Very Poor \\
\hline
\end{tabular}

Table 3. Seasonal variation for P-IBI at different sites of Al Hawizeh Marsh.

\begin{tabular}{llllll}
\hline \multirow{2}{*}{ Sites } & \multicolumn{2}{l}{ Season } & & & \\
\cline { 2 - 6 } & $\begin{array}{l}\text { Summer } \\
2005\end{array}$ & $\begin{array}{l}\text { Winter } \\
2006\end{array}$ & $\begin{array}{l}\text { Summer } \\
2006\end{array}$ & $\begin{array}{l}\text { Winter } \\
2007\end{array}$ & $\begin{array}{l}\text { Summer } \\
2007\end{array}$ \\
\hline HZ1 & 42.0 & 43.0 & 34.0 & 38.0 & 36.0 \\
HZ2 & 46.0 & 46.0 & $*$ & 50.0 & 34.0 \\
HZ3 & 38.0 & $*$ & 46.0 & 46.0 & 46.0 \\
Mean & 42.0 & 44.5 & 40.0 & 44.7 & 38.7 \\
\hline
\end{tabular}

*Sample not taken.

"Fair-Good", "Fair-Excellent" and "Good-Excellent" ecosystem condition and never declined to poor or very poor cases. The mean P-IBI values indicated that this marsh exhibit "Good" ecosystem condition throughout the study periods. Nevertheless, the mean P-IBI values were reduced from 42.0 to 38.70 throughout the successive years.

Seven sites were selected at the Central Marshes to determine P-IBI [Before Al Baghdadia (CM1), Al Hammara $\mathrm{Al}$ kabera (CM2), East of Al Hammara Al kabera (CM3), West of Al Baghdadia (CM4), Zichryi (CM5), Al Baseeta (CM6) and Al Khinziry (CM7)]. The results for different stations of the Central Marsh are shown in Table 4. Values of P-IBI ranged between 22 - 47 (Poor to Excellent ecosystem condition) indicating also more fluctuation in the status of these sites. Values of P-IBI varied between different sites and seasonal variations were evident.

The higher values were observed in CM4 site during winter 2006, while the lower values were observed in CM6 site during summer 2006.

Table 4. Seasonal variation for P-IBI at different sites of the Central Marsh.

\begin{tabular}{llllll}
\hline \multirow{2}{*}{ Sites } & \multicolumn{2}{l}{ Season } & & & \\
\cline { 2 - 6 } & $\begin{array}{l}\text { Summer } \\
2005\end{array}$ & $\begin{array}{l}\text { Winter } \\
2006\end{array}$ & $\begin{array}{l}\text { Summer } \\
2006\end{array}$ & $\begin{array}{l}\text { Winter } \\
2007\end{array}$ & $\begin{array}{l}\text { Summer } \\
2007\end{array}$ \\
\hline CM1 & $*$ & $*$ & 36.0 & 42.0 & 32.0 \\
CM2 & 24.0 & 34.0 & $*$ & 42.0 & 42.0 \\
CM3 & $*$ & 34.0 & 28.0 & 36.0 & 31.0 \\
CM4 & 26.0 & 47.0 & 32.0 & 42.0 & 32.0 \\
CM5 & 34.0 & $*$ & 28.0 & 42.0 & 30.0 \\
CM6 & 24.0 & 32.0 & 22.0 & 38.0 & 38.0 \\
CM7 & 30.0 & 42.0 & 36.0 & 42.0 & 42.0 \\
Mean & 27.6 & 37.8 & 30.33 & 40.57 & 35.29 \\
\hline
\end{tabular}

*Sample not taken. 
At site CM1, levels of P-IBI ranged between 32.0 42.0, while in CM2 values were between 24.0 - 42.0. In general, the values of P-IBI were relatively higher in winter at both sites. Similarly, the values of P-IBI were higher in winter at the site CM3. Scores of 34.0 and 36.0 were recorded in winter 2006 and 2007, respectively, whereas values of summer were 28.0 and 31.0 during the same years.

At site CM4 values of P-IBI ranged between 26.0 47.0, the highest value was recorded during winter 2006 and the lowest value at summer 2005. Higher values in winter in contrast to summer were also evident in this site. Values of P-IBI at CM5 reflected the same trend and ranged between 27.0 in summer 2006 to 42.0 in winter 2007. However, the values were reduced from 34.0 to 30.0 between summer 2005 and summer 2007. At site CM6, low value (22.0) for P-IBI was recorded at summer 2006 while the value increased during summer and winter 2007 (38.0 in both seasons). An improvement of P-IBI was evident throughout 2007 in this site. Values of P-IBI at site CM7 were between 30.0 - 42.0 during summer 2005 and summer 2007, respectively.

Generally, CM1, CM2, CM3, CM5 and CM7 sites display "Fair" or "Fair-Good" ecosystem condition, while CM4 and CM6 sites exhibit "Poor-Excellent" and "PoorGood" ecosystem condition respectively. In general, the values of P-IBI were relatively higher in winter. The mean P-IBI values also indicated that this marsh exhibit "Fair-Good" ecosystem condition throughout the study periods. With few exceptions an improvement of P-IBI was evident throughout 2007 in this marsh.

The metric scores and P-IBI values for West \& East Al Hammar Marsh were extracted for nine sites (Table 5). Values of P-IBI ranged between 22 - 44 (Poor to Good ecosystem condition) indicating also fluctuation in the status of these sites. Values of P-IBI varied between different sites and seasonal variations were also evident.

The higher values were observed in HA1 and HA9 sites during summer and winter 2007 respectively, while the lower values were observed in HA4 site during summer 2005. Generally, an improvement of P-IBI was evident in the all study sites except HA5 site throughout the successive years. Nevertheless, at Aum Nakhla (HA5), the degradation of the values was evident as they were reduced from 42.0 to 38.0 and 36.0 throughout summer 2005, 2006, and 2007 respectively, reflecting “Good-Fair" ecosystem condition. Values in this site were higher in summer 2005 and 2006 in contrast to all other stations, and vice versa for summer 2007. HA1 and HA3 sites displayed "Poor-Good" ecosystem condition while HA4 site exhibit "Poor-Fair" ecosystem condition. Undoubtedly, HA2, HA6, HA7, HA8 and HA9 sites exhibit "Fair-Good" ecosystem condition. Values in HA1 were
Table 5. Seasonal variations of P-IBI at different sites of West \& East Al Hammar Marsh.

\begin{tabular}{cccccc}
\hline \multirow{2}{*}{ Sites } & \multicolumn{2}{c}{ Season } & & & \\
\cline { 2 - 6 } & $\begin{array}{l}\text { Summer } \\
2005\end{array}$ & $\begin{array}{l}\text { Winter } \\
2006\end{array}$ & $\begin{array}{l}\text { Summer } \\
2006\end{array}$ & $\begin{array}{l}\text { Winter } \\
2007\end{array}$ & $\begin{array}{l}\text { Summer } \\
2007\end{array}$ \\
\hline HA1 & 26.0 & $*$ & $*$ & 43.0 & 44.0 \\
HA2 & 28.0 & $*$ & 28.0 & 42.0 & 42.0 \\
HA3 & 24.0 & $*$ & 38.0 & 40.0 & $*$ \\
HA4 & 22.0 & $*$ & $*$ & 32.0 & $*$ \\
HA5 & 42.0 & $*$ & 38.0 & 40.0 & 36.0 \\
HA6 & 30.0 & $*$ & 32.0 & 42.0 & $*$ \\
HA7 & 30.0 & 40.0 & 28.0 & 36.0 & 34.0 \\
HA8 & 34.0 & 36.0 & 28.0 & 40.0 & 38.0 \\
HA9 & $*$ & 40.0 & 35.0 & 44.0 & 42.0 \\
Mean & 29.5 & 38.7 & 32.43 & 39.89 & 39.33 \\
\hline
\end{tabular}

*Sample not taken.

increased from 26.0 to 44.0 through summer 2005 to summer 2007. This trend was evident at site HA2, as values increased from 28.0 in summer 2005 and 2006 to 42.0 in winter and summer 2007, respectively. At site HA3 the values raised from 24.0 to 40.0 . This case is also true for Near Al Buhaira station (HA4), as the vale increased from 22.0 to 32.0. At HA6, values ranged from 30.0 to 42.0. The higher values were observed in winter. At site HA7, values of P-IBI ranged between 28.0 and 40.0 ; generally a fluctuation in values was observed during summer, whereas degradation was evident in winter values as they failed from 40.0 to 36.0 throughout 2006 and 2007, respectively. Similarity, at site HA8 values varied between 28.0 and 40.0. A fluctuation in values was also observed during summer, whereas an improvement was evident in winter. The last station of this site was HA9, in which an improvement of the values was observed both in summer and winter throughout 2006 and 2007. Nevertheless, values were higher in winter in this site as well. In general, mean P-IBI values in West \& East Al Hammar Marsh were increased from 29.50 to 39.89 throughout the successive years.

In general, the values of P-IBI were relatively higher in winter. The mean P-IBI values also indicated that this marsh exhibit "Fair-Good" ecosystem condition throughout the study periods.

\section{Discussion}

Phytoplanktons are the first response assemblage of organisms directly affected by water quality conditions [2]. They are also the basis of food web in aquatic environ- 
ments. Therefore, it is important to monitor phytoplankton in nature. P-IBI bioassessment approach is one method of evaluating phytoplankton monitoring data. Biological metrics may be expected to provide a quantitative signal of the biota responses to environmental stressors [33].

Ten metrics of phytoplankton were used in the present study (Table 1). Phytoplankton density was used because its ease of measurement and its values are directly proportional to the productivity. Chlorophyll-a (Chl-a) metric which is the most widely used measure of phytoplankton biomass is also applied through this study. Rate of photosynthesis is directly proportional to the amount of chlorophyll, cellular concentration of Chl-a varies depending on taxonomic composition, nutrient availability, temperature and light intensity [34]. The remaining metrics used for the P-IBI in this study are either the abundance of particular group or the proportion made up by specific taxonomic group, such as Cyanophyta that often occur in bloom densities during spring and summer in mesohaline areas [35], the area which can be contrasted to Iraqi southern marshes. Diatoms (Bacillariophyta) abundance was another metric applied and it has often been used in P-IBI studies. Diatoms are often high in number in mesohaline and polyhaline areas and during the summer in tidal fresh and oligohaline areas [36].

In general, P-IBI values in AL Hawizeh marsh were reduced from 42.00 to 38.70 throughout the successive years 2005, 2006 and 2007. Density of chlorophyll-a and relative abundance of Cyanophyta and diatoms (Data not shown) might be behind such phenomenon. However, these values were undoubtedly been affected by deterioration of water quality of Tigris and Euphrates in one hand and desiccation of the marshes on the other hand which affected the soil, besides the burning process that took place several times. This ultimately led to different chemical and physical characters of water in contrast to the original status. These results come in accordance to those of zooplankton IBI (Z-IBI) in the same area (paper under preparation). A continuous monitoring and sampling in shorter intervals with considering more stations in the area may well lead to better understanding. No evidence of recovery of the status of water quality in respect to P-IBI was observed throughout this study in this region of the marshes. In contrast, degradations were evident.

Central Marsh was represented by seven stations (Figure 1). In general, values varied from Poor to Excellent ecosystem condition (22 - 47). It is evident (Table 4) that there was significant recovery in water quality with the time. Generally the Central marsh showed slight improvement in the aquatic environment in respect to the mean P-IBI values. This was particularly clear through- out stations CM2, CM6 and CM7. An increasing phytoplankton density, especially diatoms and Chlorophyta (data not shown) was observed in this area. Generally values of P-IBI were lower in summer in comparison to winter throughout almost all stations in the Central Marsh. This might be because of the decrease in population of diatoms, quantity of chlorophyll and the increase in percentage of inedible algae during summer season (Data not shown). In fact, the Central Marsh has severely faced the application of drying policy of the previous regimen. The recovery action soon after 2003 is clearly reflected on the concurrent results in the area. However, results of P-IBI came in accordance to those of Z-IBI observations at the same area (paper under preparation). The P-IBI values for West and East Al Hammar marsh were covered at nine stations (Table 5). Results reflect a progressive improvement in the values throughout 2005, 2006 and 2007, particularly in summer in most stations. However, higher values were observed in winter in contrast to summer in this marsh. Undoubtedly, effect of the drainage areas and rain might be behind this variation.

A continuous monitoring for progressive improvement should be established by using different IBI applications. Nevertheless, the results generally come in accordance to Z-IBI (unpublished paper) results that were carried out at the same time in the same area.

P-IBI has not yet been applied in any aquatic ecosystem in Iraq. Therefore, this study might lead to successive application of P-IBI in other inland waters. This investigation might lead to finding out the most useful metrics to be included in P-IBI in Iraq in the near future. In conclusion, the multimetric P-IBI was developed for the first time for the Iraqi marshes water; it can provide a useful way to monitor the changes in the water quality, which means changing in the trophic status of the water.

\section{Acknowledgements}

The fund for this work was kindly provided by Nature Iraq (NI) and Twin Rivers Institute, the American University of Iraq-Sulaimani (TRI-AUIS). We highly appreciate their support. We also acknowledge Haider Ahmed, Ali Mohammed and Hussam Jabbar for their efforts in field sampling.

\section{REFERENCES}

[1] J. R. Gammon and T. P. Simon, "Variation in a Great River Index of Biotic Integrity over a 20 Year Period,” Hydrobiologia, Vol. 422-423, 2000, pp. 291-304. doi:10.1023/A:1017060520873

[2] R. V. Lacouture, J. M. Johnson, C. Buchanan and H. G. Marshall, "Phytoplankton Index of Biotic Integrity for Chesapeake Bay and its Tidal Tributaries,” Estuaries and Coasts, Vol. 29, No. 4, 2006, pp. 598-616. 


\section{doi: 10.1007/BF02784285}

[3] J. R. Karr, “Assessment of Biotic Integrity Using Fish Communities,” Fisheries, Vol. 6, No. 6, 1981, pp. 21-27. doi:10.1577/1548-8446(1981)006<0021:AOBIUF>2.0.CO;2

[4] L. S. Fore, J. R. Karr and R. W. Wisseman, “Assessing Invertebrate Responses to Human Activities: Evaluating Alternative Approaches," Journal of the North American Benthological Society, Vol. 15, No. 2, 1996, pp. 212-231. doi: $10.2307 / 1467949$

[5] S. B. Weisberg, J. A. Ranasinghe, D. M. Dauer, L. C. Schaffner, R. J. Diaz and J. B. Frithson, “An Estuarine Benthic Index of Biotic Integrity (B-IBI) for Chesapeake Bay,” Estuaries, Vol. 20, No. 1, 1997, pp. 149-158. doi:10.2307/1352728

[6] T. Smayda, "Primary Production and the Global Epidemic of Phytoplankton Blooms in the Sea: A Linkage," In: E. M. Cosper, V. M. Bricelj and E. J. Carpenter, Eds., Coastal and Estuarine Studies, Novel Phytoplankton Blooms, Springer-Verlag, Berlin, 1989, pp. 449-483.

[7] J. L. Pinckney, H. W. Paerl, P. Tester and T. L. Richardson, "The Role of Nutrient Loading and Eutrophication in Estuarine Ecology,” Environmental Health Perspectives, Vol. 109, No. 5. 2001, pp. 699-706. doi:10.2307/3454916

[8] R. W. Alden III, D. M. Dauer, J. A. Ranasinghe, L. C. Scott and R. J. Llanso, "Statistical Verification of the Chesapeake Bay Benthic Index of Biotic Integrity,” Environmetrics, Vol. 13, No. 5-6, 2002, pp. 473-498. doi:10.1002/env.548

[9] D. D. Kane, S. I. Gordon, M. Manawar, M. N. Charlton and D. A. Culver, “A Planktonic Index of Biotic Integrity (P-IBI) for Lake Erie, A New Technique for Checking the Pulse of Lake Eric,” In: M. Munawar and R. T. Heath, Eds., Checking the Pulse of Lake Eric, Backhuys Publishers, Leiden, 2005.

[10] J. R. Karr, "Biological integrity: Along-Neglected Aspect of Water Resource Management,” Ecological Applications, Vol. 1, No. 1, 1991, pp. 66-84. doi:10.2307/1941848

[11] J. R. Karr and D. R. Dudley, "Ecological Perspective on Water Quality Goals,” Environmental Management, Vol. 5, No. 1, 1981, pp. 55-68. doi:10.1007/BF01866609

[12] A. Lumb, D. Halliwell and T. Sharma, "Application of CCME Quality Index to Monitor Water Quality: A Case Of The Mackenzie River Basin, Canada,” Environmental Monitoring and Assessment, Vol. 113, No. 1-3, 2006, pp. 411-429. doi:10.1007/s10661-005-9092-6

[13] U. Sommer, Z. M. Gliwicz, W. Lampert and A. Duncan, "The PEG-Model of Seasonal Succession of Planktonic Events in Freshwaters," Archives of Hydrobiology, Vol. 106, No. 4, 1986, pp. 433-471.

[14] D. C. Müller-Navarra, S. Güss and H. Von Storch, "Interannual Variability of Seasonal Succession Events in a Temperate Lake and its Relation to Temperature Variability," Global Change Biology, Vol. 3, No. 5, 1997, pp. 429-438. doi:10.1046/j.1365-2486.1997.00080.x

[15] W. Lampert, "Zooplankton Research: The Contribution Of Limnology To General Ecological Paradigms,” Aqua- tic Ecology, Vol. 31, No. 1, 1997, pp. 19-27. doi: 10.1023/A:1009943402621

[16] D. W. Schindler, "Detecting Ecosystem Response to Anthropogenic Stress," Canadian Journal of Fisheries and Aquatic Sciences, Vol. 44, No. S1, 1987, pp. 6-25. doi:10.1139/f87-276

[17] P. Schriver, J. Bogestrand, E. Jeppesen and M. Sondergaard, "Impact of Submerged Macrophytes on Fish-Zooplankton-Phytoplankton Interactions: Large-Scale Enclosure Experiments In A Shallow Eutrophic Lake,” Freshwater Biology, Vol. 33, No. 2, 1995, pp. 255-270. doi:10.1111/j.1365-2427.1995.tb01166.X

[18] I. Tatrai, J. Olah, G. Paulovits, K. Matyas, B. I. Kawiecka, V. Jozsa and F. Pekar, "Biomass Dependent Interactions in Pond Ecosystems: Responses of Lower Trophic Levels to Fish Manipulation,” Hydrobiologia, Vol. 345, No. 2-3, 1997, pp. 117-129. doi:10.1023/A:1002919305978

[19] APHA, WWA, WEF, "Standard Methods for Examination of Water and Waste Water," 21st Edition, American Public Health Association, Washington D.C., 2005.

[20] D. S. Rawson, “Algal Indicators of Trophic Lake Types,” Limnology and Oceanography, Vol. 1, No. 1, 1956, pp. 18-25. doi:10.4319/lo.1956.1.1.0018

[21] G. E. Hutchinson, “A Treatise on Limnology (Vol. II): Introduction To Lake Biology And The Limnoplankton,” John Wiley \& Sons, New York, 1967.

[22] S. S. Dixit, J. P. Smol, J. C. Kingston and D. F. Charles, "Diatoms: Powerful Indicators Of Environmental Change," Environmental Science and Technology, Vol. 26, No. 1, 1992, pp. 23-33. doi:10.1021/es00025a002

[23] N. Gómez and M. Licursi, “The Pampean Diatom Index (IDP) for Assessment of Rivers and Streams in Argentina,” Aquatic Ecology, Vol. 35, No. 2, 2001, pp. 173-181. doi:10.1023/A:1011415209445

[24] A. G. Solimini, M. Bazzanti, A. Ruggiero and G. Carchini, "Developing a Multimetric Index of Ecological Integrity Based on Macroinvertebrates of Mountain Ponds in Central Italy,” Hydrobiologia, Vol. 597, No. 1, 2008, pp. 109-123. doi:10.1007/s10750-007-9226-7

[25] R. Patrick and C. W. Reimer, "The Diatoms of the United States, Exclusive of Alaska and Hawaii," Monographs of the Academy of Natural Sciences of Philadelphia, Vol. 1, No.13, 1966, p. 688.

[26] G. W. Prescott, "Algae of the Western Great Lakes Area,” William C. Brown Publishers, Dubuque, 1982.

[27] W. T. Edmondson, "Fresh-Water Biology,” 2nd Edition, John Wiley \& Sons, New York, 1959.

[28] G. M. Smith, “The Fresh Water Algae of United States,” McGraw Hill Book Company, New York, USA, 1950.

[29] H. Germain, "Flore Des Diatomées, Diatomophycées," Société Nouvelle Des Éditions Boubée, Paris, 1981.

[30] T. Mizuno, "Illustration of the Fresh Water Plankton of Japan,” Hoik Publishing Company Ltd., Osaka, 1971.

[31] Environmental Protection Agency (EPA), "Best Practices for Identifying Reference Condition in Mid-Atlantic Streams," Office of Environmental Information, Wash- 
ington D.C., 2006.

[32] L. E. Astin, "Developing Biological Indicators from Diverse Data: The Potomac Basin-Wide Index Of Benthic Integrity (B-IBI),” Ecological Indicators, Vol. 7, No. 4, 2007, pp. 895-908. doi:10.1016/j.ecolind.2006.09.004

[33] G. R. Gibson, M. L. Bowman, J. Gerritsen and B. D. Snider, "Estuarine and Coastal Marine Waters: Bioassessment And Biocriteria Technical Guidance,” Environmental Protection Agency (EPA), Office of Water, 2000.

[34] R. J. Geider, H. L. MacIntyre and T. M Kana, “A Dy- namic Model of Photoadaptation in Phytoplankton,” Limnology and Oceanography, Vol. 41, No. 1, 1996, pp. 1-15. doi:10.4319/lo.1996.41.1.0001

[35] C. S. Reynolds and A. E. Walsby, "Water Blooms,” Biological Reviews, Vol. 50, No. 4, 1975, pp. 437-481. doi:10.1111/j.1469-185X.1975.tb01060.X

[36] H. G. Marshal and R. W. Alden, "Spatial and Temporal Diatom Assemblages and Other Phytoplankton within the Lower Chesapeake Bay, USA," Proceedings of the 10th International Diatom Symposium, Koeltz Scientific Books, Koenigstein, 1990, pp. 311-322. 